\title{
ON CERTAIN GENERA AND SPECIES OF CARNIVOROUS DINOSAURS, WITH SPECIAL REFERENCE TO CERA- TOSAURUS NASICORNIS MARSH.
}

\author{
By Oliver P. Hay, \\ of Washington, District of Columbia.
}

Through the liberality of the officers of the United States National Museum the writer has been enabled to prepare the following paper, which is based mainly on specimens in the possession of the Museum. Nearly all these specimens were originally collected by Prof. O. C. Marsh while acting as Vertebrate Paleontologist of the U. S. Geological Survey.

1. THE GENUS LABROSAURUS MARSH AND ITS SPECIES.

In $1879^{a}$ Marsh established the genus Labrosaurus, with his A7losaurus lucaris as the type. This species had been described in $1878^{b}$ and was based on materials found in the Upper Jurassic of Colorado. In this earliest description there was mentioned only an anterior dorsal vertebra. In the description of 1879 cervical and dorsal vertebræ and fore-limb bones were briefly described. So far as the writer knows, no part representing this species has ever been figured.

In $1884^{c}$ Marsh added a second species to the genus, Labrosaurus ferox. The only part of this animal that was mentioned is the left dentary. Marsh here made the statement that in Labrosaurus the teeth are more triangular than in the other genera of the order; but whether or not this statement had its basis in this specimen is doubtful, inasmuch as the crowns of all the teeth are missing and the roots almost wholly concealed by matrix. This dentary bone (Cat. No. 2315, U.S.N.M.) probably came from the same locality and level as the type of L. lucaris.

In $1896^{d}$ Marsh again mentioned this species and presented the same figures. In a footnote on page 163 he remarked that the skull

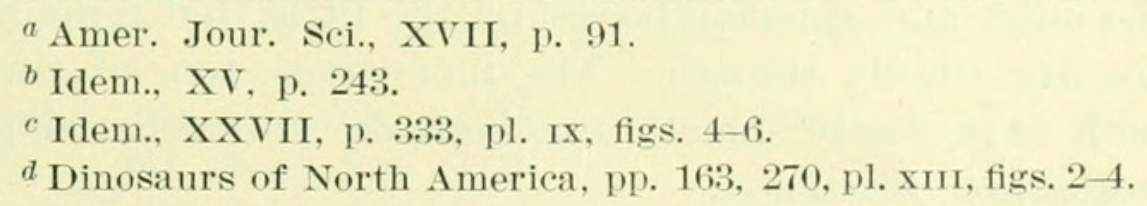

${ }^{d}$ Dinosaurs of North America, pp. 163, 270, pl. xIII, figs. $2-4$. 
of Allosaurus ferox had an aperture in the maxillary in front of the antorbital opening. The context appears to indicate that "Allosaurus ferox" is a slip of the pen for Allosaurus fragilis, just as Labrosaurus ferox seems to be called Labrosaurus fragitis on page 270 . At any rate, this is the only mention that Marsh made of the skull of either $L$. ferox or $A$. fragilis. In the definition of the family Labrosauridæ ${ }^{a}$ he mentioned no part of the skull but the lower jaw.

On page 270 of the work last cited Marsh referred a third species to Labrosaurus, namely, L. sulcatus. This is done in the explanation of Plate XIII, fig. 1; and, so far as the writer is aware, Marsh nowhere else mentioned this species. Three views of a single tooth are given, but there is no description and no statement as to the origin of the specimen.

Inasmuch as no teeth or parts of the skull were, so far as Marsh informs us, present with the type of L. lucaris, and only teeth or parts of the lower jaw appear to have been represented in the types of the other species, one is at a loss to understand on what grounds the second and third species were referred to Labrosaums. Furthermore, it may be worth while to inquire whether $L$. ferox and $L$. sulcatus are congeneric.

The type of L. sulcatus is a tooth which, judging from Marsh's figures, presents a crown $30 \mathrm{~mm}$. high, with a base whose antero-posterior diameter is $12.5 \mathrm{~mm}$. and whose transverse diameter is $12 \mathrm{~mm}$. There is a posterior face which appears to have been somewhat concave, its outer boundary being formed by a crenulated, its inner by a smooth, carina. The outer face of the tooth is ornamented at the base by about eight ridges, of which only three remain at the apex. The inner and the posterior faces are represented as being smooth.

As already stated, the jaw of $L$. ferox presented to Marsh little or nothing of the teeth. The crowns of all the functional teeth are missing and the roots were almost wholly concealed by matrix. A section of the base of the crown furthest in front showed above the enveloping sandstone. Of this matrix the writer has removed enough to expose a part of the outer and front faces of the tooth. The inner face had been almost wholly absorbed by the successional tooth, of whose apex about $9 \mathrm{~mm}$. are now laid bare. The functional tooth had an antero-posterior diameter of $15 \mathrm{~mm}$. and a transverse diameter of $9 \mathrm{~mm}$. The latter diameter was near the front of the tooth, a fact which indicates that the anterior cutting edge had subsided far above the base of the crown. The hinder edge seems to have reached the base. The outer and anterior faces and the little that remains of the inner face are wholly smooth. The inner face, too, of the successional tooth is perfectly smooth and both the anterior and posterior cutting edges are crenulated.

${ }^{a}$ Amer. Jour. Sci., L, 1895, p. 493 ; Dinosaurs of North America, p. 239. 
The writer has likewise exposed the tooth which was displacing the sixth functional tooth, the outer wall of whose base still remains. The apex of the successional tooth is broken off. The long diameter at the section thus furnished is $8.5 \mathrm{~mm}$.; the short diameter, $5.5 \mathrm{~mm}$. The inner and outer faces are equally convex, both are smooth, and both cutting edges are crenulated.

Such being the structure of the teeth of the types of Labrosaums ferox and $L$. sulcatus, it becomes evident that the two species belong: to quite distinct genera and almost certainly to different families; but which of them belongs to Labrosaurus, if either, can be determined only by future discoveries.

In the lower jaw of L. ferox there were plainly 12 teeth. The first was placed $63 \mathrm{~mm}$. behind the tip of the jaw, between which and the tooth there is a deep notch. The posterior part of the dentary is bent downward in an extraordinary way, somewhat like that of a fringilline bird. These peculiarities show that this species belongs to a family entirely distinct from that typified by Allosaumes.

\section{NOTE ON ANTRODEMUS LEIDY.}

In the writer's Bibliography and Catalogue of the Fossil Vertebrata of North America, 1902, p. 489, all the species of Labrosaums are referred to Antrodemus Leidy. The responsibility of this assignment must be shared by the writer and his friend, Frederic A. Lucas. The writer is now inclined to recede from the position there taken.

Antrodemus was established by Leidy ${ }^{a}$ on the hinder half of a caudal vertebra of some carnivorous dinosaur. This vertebra (Cat. No. 218, U.S.N.M.) had been found by Dr. F. V. Hayden in Middle Park, Colorado, and was supposed to have come from Cretaceous deposits. Now, inasmuch as no caudal vertebræ have been described or even mentioned in connection with any of the species of Labrosaurus, and inasmuch as it is very doubtful if Antrodemus valens came from the same level as Labrosaurus tucaris, there appears to be no sufficient reason for displacing Marsh's generic name in favor of Antrodemus.

By an inexplicable error the writer $^{b}$ referred to Antrodemus the remains described by Marsh as Allosaurus medius. These remains had been found in Potomac deposits at Muirkirk, Maryland, and were placed by Marsh in Allosaumes only provisionally.

\section{ON ALLOSAURUS MARSH AND CREOSAURUS MARSH.}

The genus Creosaums is a subject of discussion. Dr. S. W. Willis$\operatorname{ton}^{c}$ has called attention to the fact that a lumbar vertebra which

${ }^{a}$ Proc. Acad. Nat. Sci. Phila., 1870, p. 3 ; Contrib. Ext. Vert. Fauna West. Terrs., 1873, p. 267, pl. xv, figs. 16-18.

${ }^{b}$ Bibliog. and Cat. Foss. Vert. N. Amer., p. 489.

${ }^{c}$ Amer. Jour. Sci., XI, 1901, p. 111.

Proc. N. M. vol. $\mathrm{xxxv}-08-23$ 
Marsh ${ }^{a}$ first attributed to Allosaums fragitis was afterwards, without expression of reasons therefor, referred ${ }^{b}$ to Creosaurus atrox. Nevertheless, we can hardly suppose that Marsh ever regarded this vertebra as a part of the type of $A$. fragitis; and, if we can depend on Marsh's figure, said to be one-sixth the natural size, this vertebra is not the one whose measurements are given by Marsh. inasmuch as its length is $119 \mathrm{~mm}$., instead of $105 \mathrm{~mm}$.

The type of Creosaurus atrox is a left ilium, which Marsh figured more than once. ${ }^{c}$ Marsh informs us in his earliest description that there were some teeth which he referred to this species and which had trihedral crowns and crenulated cutting edges; and he has figured the right premaxillary with its five teeth. This premaxillary is probably a part of the individual that furnished the ilium. In the lastmentioned citation Marsh stated that the anterior end of the ilium might be imperfect. He gave, as the extreme length of the bone, $700 \mathrm{~mm}$. It may be confidently assumed that the anterior border of the bone had approximately the form seen in the ilium of Allosaurus ${ }^{d}$ and that the front of the pubic process has suffered some loss. Almost certainly Marsh was mistaken when he suggested that a prepubic bone had articulated with this process. The original length of the ilium may be regarded as having been close to $720 \mathrm{~mm}$. It is proposcd to compare some of its dimensions, taken from Marsh's figure, with corresponding dimensions taken from the ilium, also $720 \mathrm{~mm}$. long, of the specimen of Allosaums fragitis, now in the U. S. National Museum, Cat. No. 4734, from which were made fig. 2, Plate X, and fig. 2, Plate XI, of Marsh's Dinosaurs of North America. The second column under each species presents the percentage which each measurement is of the length of the ilium.

Table of measurements and percentages.

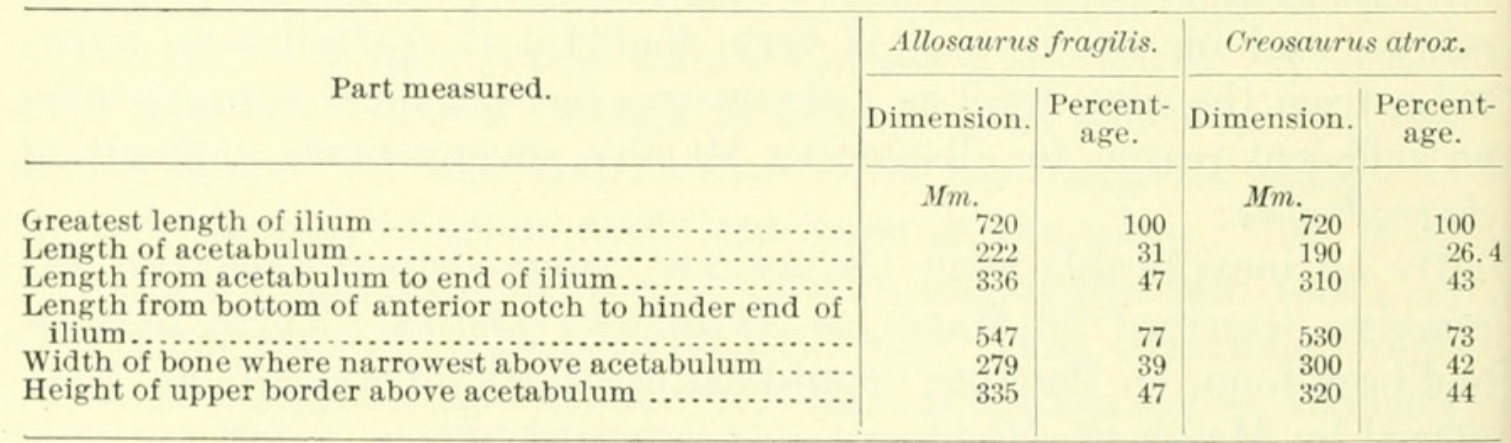

It will be observed that the differences in the measurements of the two species do not reach 5 per cent of the length of the bone. The

${ }^{a}$ Amer. Jour. Sci., XVII, 1879, pl. x, figs. 3, 4.

$b$ Idem, XXVII, 1884, p. 334, pl. xIv, figs. 3, 4.

$c$ Idem, XV, 1878, p. 243, figs. 1, 2 ; XVII, 1879, p. 90, pl. x, figs. 1, 2 ; XXVII, 1884, p. 335, pl. xıv, figs. 1, 2 ; Dinosaurs of N. Amer., 1896, pl. xII, figs. 2, 3.

${ }^{d}$ Dinosaurs of North America, pl. $\mathrm{x}$, fig. 2. 
acetabulum of Creosaums is relatively small, the neck above the pubic and ischiadic processes broad, and the crest high above the acetabulum. The notch above the pubic process does not extend backward as far as the front of the acetabulum; but there is another ilium in the U. S. National Museum (Cat. No. 2323), believed to belong to Allosaums fragilis, which is intermediate in the depth of this notch. Whatever may be true of other parts of the skeleton of Creosaurus, there do not appear to be any characters in the ilium that distinguish it generically from Allosaurus. The metapodial whose measurement was given by Marsh ${ }^{a}$ has the same length relative to the length of the ilium that the fourth metapodial of Allosaurus fragilis has to its ilium, being about 40 per cent.

Dr. S. W. Williston ${ }^{a}$ has published a figure of a scapula, coracoid, and some fore-limb bones which certainly differ from those of Allosaurus; but there is as yet no certainty that any of these belong to Creosaurus. Osborn ${ }^{b}$ has figured as that of Allosaurus a scapula which differs greatly from that of Marsh's specimen and which resembles closely Williston's figure of the scapula thought to belong to Creosaums.

Osborn has likewise described and figured $^{c}$ a skull as that of Creosaums; but he grants that the genus has not been clearly separated from Allosaurus. When this figure is compared with that of a skull identified by Osborn ${ }^{d}$ as Allosaums no important differences are discoverable.

The skull last mentioned and the scapula figured by Osborn belong to the fine skeleton of a carnivorous dinosaur which is on exhibition in the American Museum of Natural History in New York. It is to be regretted that there has not yet appeared a full critical description of this animal. However, a popular account of it, authorized by Professor Osborn, was published in December, 1907, ${ }^{e}$ by Mr. Walter L. Beasley, and was accompanied by three figures reproduced from photographs. In this article Professor Osborn contributed a paragraph in which he identified the reptile as Allosaurus. Almost certainly, however, it is not Allosaurus fragilis, for various reasons. While the length of the fore limbs of the American Museum specimen has almost exactly the same ratio to the length of the hinder limb that we find in the type of Allosaurus fragitis, the various segments of the fore limbs of the two are quite unlike. There appears to be no good reason why one cannot rely on Marsh's figure of the fore limb and shoulder girdle. In the New York specimen the hand is relatively enormous, being fully as long as the humerus

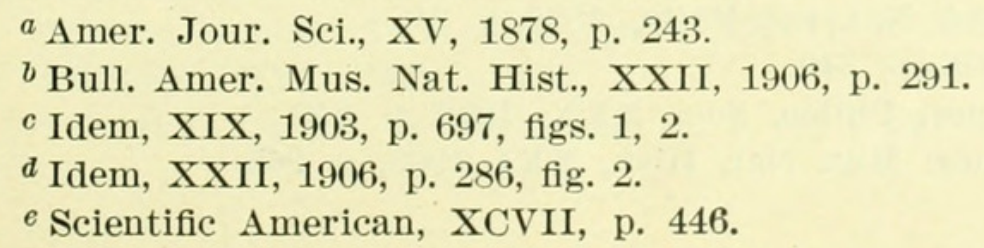


and one and three-fourths times the length of the fore arm; while in Allosaurus fragitis the hand is about six-tenths as long as the humerous and about equal to the fore arm. The deltoid crest of the New York specimen is broader and more abruptly formed than in Allosaurus fragilis and the bones of the fore arm are much stouter. When the figures of the New York specimen are compared with those of the shoulder girdle and limb published by Williston, as mentioned, one finds the resemblances between the common parts to be very close indeed. It seems probable that the American Museum specimen belongs to Creosaurus rather than to Allosaurus.

4. THE GENERA DEINODON LEIDY, DRYPTOSAURUS MARSH, AND ALBERTOSAURUS OSBORN.

Mr. Lambe has published ${ }^{a}$ an instructive description of two skulls of a species of carnivorous dinosaur under the name of Dryptosaurus incrassatus. The name Lalaps incrassatus ( $=D$. incrassatus) was first applied by Cope $^{b}$ to two teeth found in the Judith River beds, Montana; afterwards ${ }^{c}$ to a dentary bone from the same region and level and retaining some of the teeth. Later ${ }^{d}$ Cope described under the same name the two skulls which Lambe has made the subject of his communication. These skulls were derived from the beds of the Edmonton series in Alberta, deposits that are probably equivalent to the Ceratops beds of Wyoming.

Lambe concluded, and without doubt with justice, that the Edmonton skulls did not belong to the same species as the teeth and the dentary bone that had originally borne the name Lataps incrassatus. He then proceeded to do two things that are open to criticism. He identified the Judith River specimens alluded to as being probably Deinodon horridus Leidy, and then proposed that the Edmonton specimens should hereafter be regarded as the types of Dryptosaurus incrassatus.

That the Judith River specimens described by Cope do not belong to $D$. horridus seems evident from the fact that none of the various teeth originally described by Leidy under this name had the transverse diameter greater than that parallel with the jaw. As regards the transfer of a specific name from one type to another, it is needless to remark that this is not permitted by the rules of nomenclature. Mr. Lambe should have described those skulls under a new specific name. This was later done by Osborn, ${ }^{e}$ who bestowed on them the name Albertosaurus sarcophagus.

${ }^{a}$ Contrib. Canad. Palæont., III, 1904, Pt. 3, pp. 5-27, pls. I-vIII.

${ }^{b}$ Proc. Acad. Nat. Sci. Phila., 1876, p. 248.

${ }^{c}$ Idem, 1876, p. 340.

${ }^{d}$ Proc. Amer. Philos. Soc., XXX, 1892, p. 240.

${ }^{e}$ Bull. Amer. Mus. Nat. Hist., XXI, 1905, p. 265. 
Whether or not Osborn's genus Albertosaurus will prove to be well founded only future discoveries can decide. The Edmonton beds are considerably younger than the Judith River. In the interval that elapsed, the genera of dinosaurs may have wholly changed; but we are not certain of this. That Dryptosaurus, an Upper Cretaceous genus, the type of which was found in New Jersey, may have existed in the nearly contemporaneous Judith River epoch and region is wholly probable. Trachodon is believed by paleontologists to include species from the Upper Cretaceous of New Jersey, the Judith River beds of Montana, and the Ceratops beds of Wyoming. Ornithomimus appears to have continued from the Eagle epoch, older still than the Judith River, ${ }^{a}$ and from the Judith River epoch itself, to the Edmonton. ${ }^{b}$ The type of the genus $O$. velox was found in the Denver beds. ${ }^{c}$ Even many species of vertebrates of the Ceratops beds are as yet indistinguishable from those of the Judith River, as noted especially by Williston. ${ }^{d}$

It seems likely that Osborn has laid greater emphasis on the probable generic distinctness of the dinosaurs from the Upper Cretaceous of New Jersey, the Belly River, the Judith River, and the Edmonton beds respectively, because of his view that the Belly River beds do not belong to the Upper Cretaceous, but to a much lower, though as yet undefined, horizon. ${ }^{e}$

Osborn's definition of Dryptosaurus does not seem to exclude from that genus the Judith River dentary described by Cope. In both, some of the anterior mandibular teeth had the long diameter of the section at the base of the crown directed transversely to the axis of the jaw. Furthermore, in case the species incrassatus does not belong to Dryptosaurus, the establishment of a new genus for its reception appears to be required. In any case, Osborn's mild reproach that Lambe had referred the Edmonton skulls to a New Jersey genus loses its force. To say that Lambe had referred those skulls to a Judith River species is incorrect, as has been shown above.

In Albertosaurus sarcophagus a tooth that may be regarded as the first incisor has, according to Lambe's description, the hinder face flat, so that the cross section is D-shaped, while the corresponding tooth of Dryptosaurus incrassatus has the anterior cutting edge brought far around toward the inner side of the tooth, thus representing a stage somewhat more primitive than that of Albertosaurus sarcophagus. The species may therefore be generically distinct. As

${ }^{a}$ Hatcher, Bull. U. S. Geol. Surv., No. 257, p. 87.

${ }^{b}$ Lambe, Contrib. Canad. Palæont., III, Pt. 2, 1902, p. 53.

${ }^{c}$ Cross, Monogr. U. S. Geol Surv., XXVII, p. 227.

${ }^{d}$ Science, XVI, 1902, p. 952.

${ }^{e}$ Contrib. Canad. Palæont., III, Pt. 2, pp. 7-19. 
regards the alveolar partitions, there appears to be little difference. On this point compare Cope's description ${ }^{a}$ and that of Lambe on page 16 of his paper cited above.

That Albertosaurus is distinct from Deinodon is still more doubtful. Osborn has presented what he regards as the probable characters of the latter genus. ${ }^{b}$ Now, of the maxilla and the mandible of Deinodon nothing is known; hence nothing of the alveolar partitions and triangular interdental plates. It is not known that the anterior mandibular teeth were large and truncate in cross section. The small tooth with $\mathbf{D}$-shaped section which was figured by Leidy ${ }^{c}$ may have occupied the place of first mandibular incisor, just as it does in Albertosaurus sarcophagus. ${ }^{d}$ What the structure of the premaxillary teeth of Deinodon was is not known. It is in the premaxillæ that may have been inserted those large teeth with $\mathbf{D}$-shaped section that are represented by Leidy's figures 35-40 of the plate cited. Dryptosaurus, as represented by Cope's Judith River dentary, was, at most, probably not far removed from Deinodon, and in close proximity to that dentary Cope found a large tooth with D-shaped section. This he thought had been in the position of an upper canine; but it might quite as well have been an upper incisor. In case all the teeth originally referred by Leidy to Deinodon really belonged to one animal, it seems to me that the present evidence indicates that the small teeth with D-shaped section belonged in the front of the lower jaw, while the large teeth with similar section belonged in the premaxillæ. And the writer sees nothing to exclude Albertosaurus sarcophagus from association with the species of Deinodon.

It may not be improper to remark here that Osborn erred when he stated $e$ that the present writer has held the view that the name Deinodon is invalid. The writer needs only cite a paper in the American Geologist $f$ and his Bibliography and Catalogue of Fossil Vertebrata of North America ${ }^{g}$ to show that he has both used and defended the use of Deinodon. Nor is it correct to say that Cope rejected the name because of the indefiniteness of the type. Cope regarded the name as preoccupied by Dinodon of Dumeril and Bibron, as I have shown in the article cited in the American Geologist.

In his interesting paper here considered Osborn appears to imply that Leidy's generic name Aublysodon may become available in case it shall be shown that those teeth originally referred to Deinodon

${ }^{a}$ Proc. Acad. Nat. Sci. Phila., 1876, p. 342.

${ }^{b}$ Bull. Amer. Mus. Nat. Hist., XXI, 1905, p. 261.

c Trans. Amer. Philos. Soc., XI, 1859, pl. Ix, figs. 41-45.

${ }^{d}$ Lambe, Contrib. Canad. Palæont., III, Pt. 3, p. 11.

e Contrib. Canad. Palæont., III, 1902, p. 18; Bull. Amer. Mus. Nat. Hist., XIX, 1905, p. 259.

$f$ Vol. XXIV, 1899, p. 346.

$g$ Page 488. 
which had a $\mathbf{D}$-shaped section belonged in fact to an animal distinct from the one which possessed the saber-shaped teeth. The writer regards as remote the contingencies under which this is possible.

Leidy applied the name Deinodon to teeth of various forms and sizes, without specifying any as types. Cope was the first who restricted the name and he ${ }^{a}$ applied it to those teeth with the D-shaped section; and as first reviser his act must be respected. Leidy's having first mentioned the saber-shaped teeth in his description, and given them a lower number on his plate certainly have nothing to do with the matter, and his subsequent application of the name Aublysodon to the teeth with $\mathbf{D}$-shaped section can avail nothing against Cope. On this point Canon XXI of the American Ornithologists Union's Code of Nomenclature and the remarks following it may be consulted.

To the present writer it seems that there are only two possible conditions under which. Aublysodon may become available. The first is that hereafter it shall be found that the name Deinodon had been employed for some animal before its use by Leidy. The second is that it shall at some time be shown that the tooth represented by Leidy's figures 35 and 36 belonged to one genus, while that represented by figures $37-40$ belonged to another. In such a case it may possibly be allowable to employ Deinodon horridus for one tooth, Aublysodon mirandus for the other. The teeth represented by Leidy's figures 41-45 are excluded, inasmuch as Leidy expressed a doubt respecting their relation to the other teeth. This expression of doubt renders nugatory Marsh's restriction of the name mirandus to these teeth. ${ }^{b}$

5. OBSERVATIONS ON THE SKULL OF CERATOSAURUS NASICORNIS MARSH.

The skull which forms a part of the type of Marsh's Ceratosaurus nasicornis belongs to the U. S. National Museum and bears the catalogue No. 4735 .

During its entombment this skull became somewhat distorted and much compressed, so that its thickness, from side to side, is now only about 4 inches. Marsh's figures present a somewhat restored view of the skull. Furthermore, at the time that these figures were made the matrix had not been removed from the orbits and the antorbital vacuities, and consequently the bones of the palate were not depicted. However, the matrix seems to have been removed at the time that Marsh wrote the description for his Dinosaurs of North America. Inasmuch as this is probably the most complete known skull of a carnivorous dinosaur, it has been thought proper to present photo-

${ }^{a}$ Proc. Acad. Nat. Sei. Phila., 1866, p. 279.

${ }^{b}$ Amer. Jour. Sci., XLIV, 1892, p. 174. 
graphs of both sides of it and to figure and describe as accurately as possible the lower jaw and the palatopterygoid region. Four text figures, two being reproductions of retouched photographs, are fur-

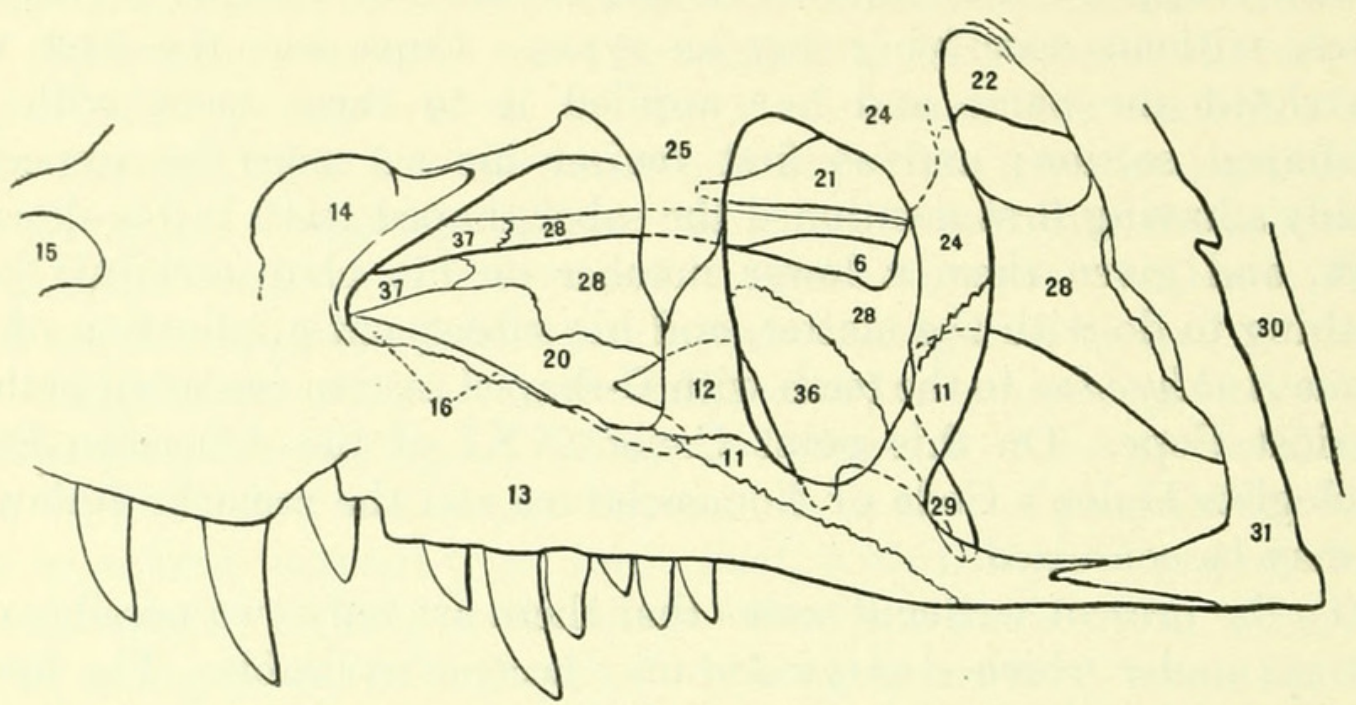

Fig. 1.-Ceratosaurus nasicornis. $\times \frac{1}{6}+$. Right side of skull. For explanation OF NUMERALS SEE FIG. 2.

nished. Fig. 1, drawn to scale, shows the most important parts of the left side of the skull. It is intended to illustrate especially the structures forming the roof of the mouth.

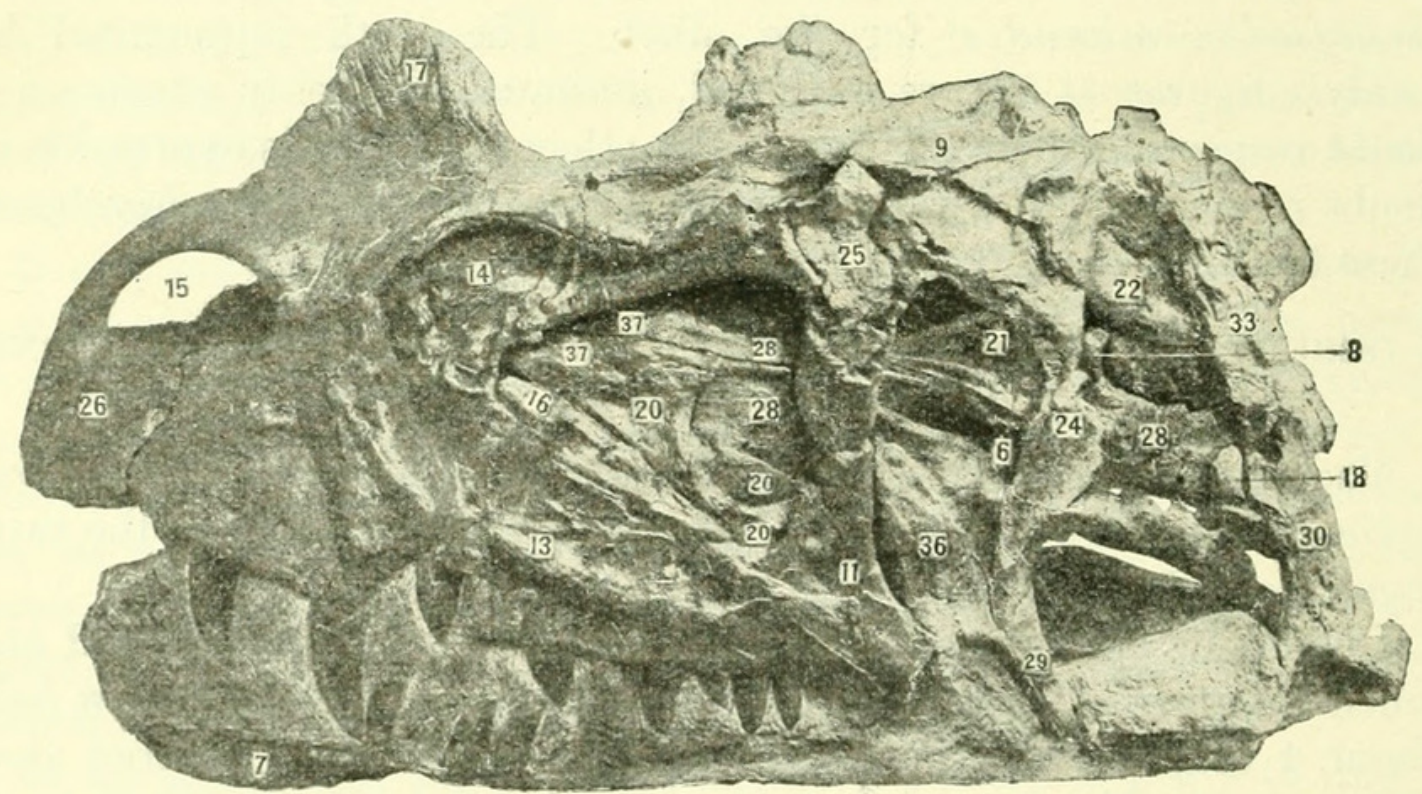

Fig. 2.-Ceratosaurus nasicornis. $\times \frac{1}{8}+$.

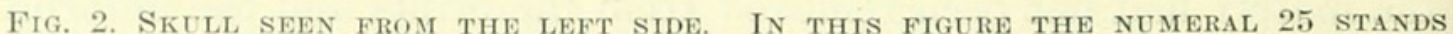
ON THE MATRIX WHICH FILLS THE CAVITY OF THE PREFRONTAL BONE, THE OUTER WALL OF WHICH HAS BEEN BROKEN AWAY. THE UPPER 37 IS PLACED ON THE RIGHT VOMER; THE UPPER 28 ON THE RIGHT PTERYGOID.

\footnotetext{
1. Angular

2. Antorbital vacuity.

3. Articular.

6. Cleft between ptery goids.

7. Dentary.

8. Epipterygoid.

9. Frontal.

10. Hyoid bone

11. Jugal.

12. Lachrymal bone.
}

13. Maxilla.
14. Maxillary depression.
15. Nares, external.
16. Nares, internal.
17. Nasal horn.
18. Occipital condyle.
19. Orbit.
20. Palatine.
21. Parasphenoid.
22. Parietal.
24. Postrontal.

24. Postfrontal.
25. Prefrontal.

26. Premaxilla.

27. Postnarial foramen.

28. Pterygoid.

29. Pterygoid process.

30. Quadrate.

31. Quadratojugal.

33. Squamosal.

34. Suprangular.

36. Transverse bone.

37 . Vomer. 
In taking the photographs it has been thought better to remove the lower jaw of the left side, a part of the jugal, the quadratojugal, and the articular end of the quadrate (fig. 2), thereby presenting to better advantage the bones of the palatopterygoid arch. On the right side of the skull (fig. 3) are seen all the bones that bound the orbit, the infratemporal fossa, and the antorbital vacuity. The postfronto-squamosal bar remains. On the left side this is missing.

On the right side is seen the prefrontal protuberance complete. The anterior half or more of this process is scooped out (fig. 3, in front of 25), the upper part deepest, so that the prefrontal bone is a mere shell. From the hinder border of this excavation a perpendicular slit $30 \mathrm{~mm}$. long opens into a cavity that occupies the descending process of the prefrontal. On the left side the outer wall of the prefrontal is broken away, so that the matrix filling the cavity

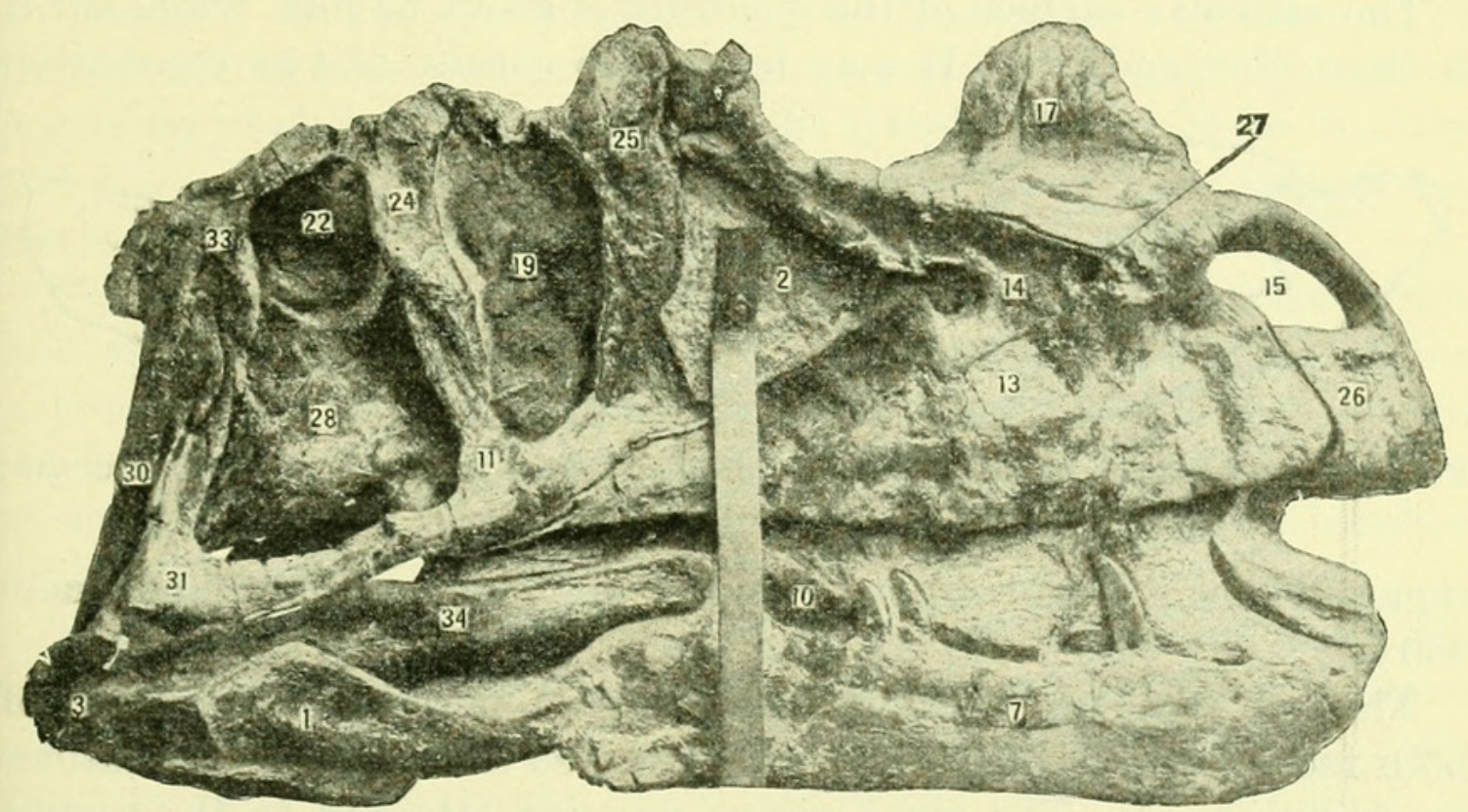

Fig. 3.-Ceratosaurus nasicornis. $\times \frac{1}{6}+$, SkUll seen from the right side. For explanation of Numerals, See Fig. 2.

is exposed. In fig. 2 the numeral 25 is placed on the matrix which fills the cavity. The opening into the cavity is in front of the 25 .

On the left side the crowns of three teeth belonging to the lower jaw are seen adhering to the matrix. A large part of the crown of the fourth maxillary tooth, which was pushing itself through the bone, has at some time been exposed by removal of bone. On the right side most of the maxillary teeth are missing. The large tooth lying in the matrix with the apex pointing backward seems, from its narrowness, to be a mandibular tooth. Three mandibular teeth remain in place.

It will be observed that there is a large uneven depression in front of and partly above the antorbital vacuity (fig. 2, numeral 14). This is not well shown in Marsh's figure. This depression probably corresponds to the postnarial vacuity figured by Lambe as belonging 
to Dryptosaurus and that figured by Osborn as belonging to Creosaurus and Allosaurus. There is a similarly placed vacuity in the skull of Diplodocus, whose nasal openings are located far toward the rear of the skull. Inasmuch as this vacuity in the Theropoda and in Diplodocus appears to be wholly in the maxillary bone, it might be well called the maxillary vacuity. On the left side of the skull of our specimen of Ceratosaums no actual opening is seen through the bone, but on the right side, near the front of the depression, $47 \mathrm{~mm}$. behind the nostril, there seems to be a foramen.

Baur stated ${ }^{a}$ that there was a foramen between the outer surface of the quadrate and the quadratojugal, as in Sphenodon. The present writer has not observed this. Seen from behind there is a considerable depression where this foramen might be expected to occur; but the bone, though thin, seems to be continuous.

The articular surface of the quadrate is about $65 \mathrm{~mm}$. wide, but it is short fore and aft. It may be said to consist of two convexities

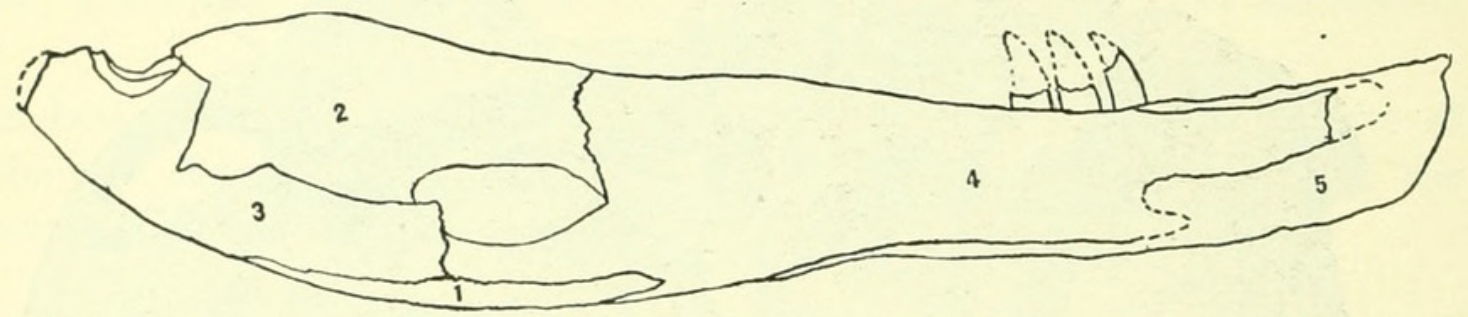

Fig. 4.-Ceratosaurus nasicornis. × 2, Suprangular ; 3, Articular ; 4, Splenial ; 5, Dentary.

separated by a broad groove running obliquely outward and backward.

The left ramus of the lower jaw (fig 4) permits examination of both faces, but it has been somewhat restored and in places the sutures are not distinct. The right ramus remains attached to the matrix and presents only the outer face. Fig. 3 shows distinctly that the bones of its hinder part have been somewhat displaced. The supraangular (fig. 4, numeral 2) is seen to form the upper border of the jaw behind the dentary, extending forward above the lateral foramen in the jaw. The angular, 1 , is seen beneath the foramen. Its hinder end has probably been broken off, but the bone probably did not reach the angle of the jaw. The relations of this bone to its neighbors was probably the same as shown by Lambe's figure, ${ }^{b}$ except that the bone regarded by him as the hinder end of the dentary is almost certainly the angular. In Ceratosanrus the angular continues forward a little in front of the foramen. Here its outer face is overlapped by a process of the dentary, 5 , while on the lower border of the jaw a process of the splenial, 4, presses itself between two processes of the angular.

${ }^{a}$ Amer. Naturalist, XXV, p. 446.

${ }^{b}$ Contrib. Canad. Palæont., III, Pt. 3, pl. vinI, fig. 20. 
Lambe has represented the angular as appearing hardly at all on the outside of the jaw, but extensively on the inner side. What he regards as the angular is almost certainly a long process of the articular, such as occurs in the lizards. If in Lambe's specimen there is really a suture between the articular and the bone called by him the angular the latter is a distinct prearticular. Quite certainly in Ceratosaurus the suture does not exist. Here the process reaches the foramen and a little below it (fig. 4, numeral 3). The cotylus of the articular, to suit itself to the quadrate, presents two grooves separated by an oblique ridge. The articular extended but little behind the cotylus.

What Lambe calls the presplenial, following Baur, the present writer regards as a part of the true splenial, the other part being what Lambe has recognized as the splenial. Thus the existence of the suture represented by Lambe between his splenial and presplenial is questioned. In the species described by Lambe the anterior end of the splenial is very slender; in Ceratosaurus the splenial throughout nearly its whole length rises close to the alveolar border of the dentary and descends close to the lower border of the jaw. As it approaches the symphysis its lower border seems to have risen somewhat.

Fig. 1 represents a view of the left side of the skull, that which best shows the bones of the palate. In the fossil the bones of the palate stand nearly perpendicular, but without doubt this is to a great extent due to crushing. They probably sloped upward and inward at an angle of about 45 degrees, or more probably they formed a vaulted roof for the mouth.

The postero-inferior process of the pterygoid (fig 2, numeral 28) joins the inner border of the quadrate at a point about $55 \mathrm{~mm}$. above the articulation of the latter bone with the lower jaw. The posterosuperior process rose to the upper end of the quadrate. Whether or not the pterygoid articulated with the quadrate the whole distance between the two points mentioned is somewhat uncertain. On the left side of the skull a considerable part of the pterygoid from the middle of the quadrate forward is broken away. Marsh neither mentions any vacuity here nor does he represent it in his figure. On the right side there is a gap between the two bones, extending about $55 \mathrm{~mm}$. along the border of the quadrate and forward from it less than 15 $\mathrm{mm}$. It seems probable that in life this gap was filled in with bone. This region is represented in the figure as it appears on the right side. In Sphenodon the quadrate sends forward a broad process between the upper and lower processes of the pterygoid. It is quite certain that this was not the case in Ceratosaurus.

Marsh informs us that there is a very short, thin epipterygoid closely articulated by suture with the pterygoid. The position of the suture is obscure, but it was doubtless present. Marsh was probably mistaken when he affirmed that the upper end of the epipterygoid 
articulated with the postfrontal. Its connection must have been with the border of the parietal. The epipterygoid of the left side has its upper end missing (fig. 2, numeral 8). On the right side this bone is uninjured. Its upper end is moved well outward toward the postfrontal, but it is probably joined to the parietal. The suture between the latter bone and the postfrontal is obscure. Just behind the base of the epipterygoid the width of the pterygoid is $64 \mathrm{~mm}$.

The inner and anterior end of the transverse bone (figs. 1, 2, numeral 36) overlaps the outer border of the pterygoid, as if it had been pressed somewhat out of its natural relations; but in both Sphenodon and Cyclura the transverse bone overlaps the pterygoid. From the outer border of the pterygoid and of the transverse bones a strong process, 29, descends to a point a little below the upper border of the lower jaw. Marsh indicates that this process belonged wholly to the transverse, but the suture between the two bones is distinct. The transverse measures $160 \mathrm{~mm}$. from its inner end to the extremity of the process mentioned. Just in front of the inner end of the transverse the pterygoid is $45 \mathrm{~mm}$. wide.

The sutures separating the pterygoid, the palatine, and the vomer are not as distinct as could be desired. Nevertheless their courses may be made out more or less satisfactorily. The bones of the right and left sides did not articulate on the midline. Doubtless there was, at least posteriorly, a considerable interval between them. In the skull, as preserved, the rounded inner, or upper, border of the bones of the right side rise several millimeters above those of the left side.

Mostly hidden by the lachrymal and the jugal, in a side view of the skull, is a considerable vacuity in the bones of the roof of the mouth. Its fore and aft extent is $90 \mathrm{~mm}$. This is called by Lambe the suborbital vacuity. It seems to correspond to the postpalatine foramen of lizards, turtles, and sphenodon. It is bounded behind by the transverse and mesially, in part, by the pterygoid. In fig. 2 the vacuity is mostly hidden by the lachrymal. A part of it, with light shading, appears between the two numerals 20 ; the hinder part is shaded dark and is in front of numeral 36.

Another fissure in the roof of the mouth is seen through the antorbital vacuity and is situated just above the border of the maxilla. This is the internal nasal passage (fig. 2, numeral 16). It extends forward to the anterior end of the antorbital vacuity and backward to a bar of bone that bounds the postpalatine vacuity in front. The whole extent of the internal nasal passage, as seen, is $85 \mathrm{~mm}$. Possibly it extended forward some distance beyond the front of the antorbital vacuity.

The bone that lies between the postpalatine vacuity and the nasal passage is undoubtedly the palatine (figs. 1, 2, numeral 20). A 
branch of this bone runs backward against the inner face of the maxilla, its hinder extremity being hidden by the maxilla, the front end of the jugal, and the base of the lachrymal. The hinder border of the bone sweeps around and bounds in part the postpalatine vacuity mesially. The suture between the palatine and the pterygoid appears to be where drawn in fig. 1, running first directly forward from the inner side of the postpalatine vacuity to a distinct ridge, then following upward and inward this ridge about $25 \mathrm{~mm}$. Behind this ridge the fibers of the bone are directed fore and aft; on the ridge and in front of it they are directed upward. There can be little doubt that the surface behind the ridge belongs to the pterygoid; that in front of it, to the palatine.

When carefully examined, the ascending suture appears to end about $20 \mathrm{~mm}$. below the upper border of the plate of bone of this left side. From this point there appears to be a suture that runs forward some distance. Above this supposed suture the bone fibers are directed forward; below it, near the ridge, they are directed upward; more anteriorly they run upward and forward. The part of the bone with ascending fibers is quite certainly the upper and anterior portion of the palatine. One can not be certain how far forward this bone extends; it seems to reach almost to the front of the antorbital vacuity, ending there in a point. It is possible, however, that it ends on the border of the nasal passage about $35 \mathrm{~mm}$. behind the front of the antorbital vacuity.

The bone lying above the palatine and at the front of the antorbital vacuity is undoubtedly the left vomer (figs. 1, 2, numeral 37). This appears to extend backward to meet the pterygoid above the palatine, as drawn in the figure. If this is the case, the palatines did not meet at the midline of the palate. Lambe concluded that in the skull of his Dryptosaurus incrassatus (Albertosaurus sarcophagus Osborn) the palatines were in contact posteriorly.

If the conclusions arrived at here are correct, the internal narial passage was bounded inwardly almost wholly by the palatine; only slightly by the vomer. In any case, the vomer takes a less important part in the border of the internal nostril than it does in either Sphenodon or Cyclura. In Cyclura, perhaps in lizards generally, the palatines meet in the midline, thus shutting off the pterygoids from the vomers. In Sphenodon the pterygoids join the vomers. In the broad union of the pterygoid with the quadrate and the union of the pterygoid with the vomer, Ceratosaurus appears to show closer relationship with Sphenodon than with the lizards and crocodiles. In the crocodiles access to the supratemporal fossa from behind is cut off above the paroccipital process, but not from below.

To what extent the internal nasal passage was bounded exteriorly by the palatine in Ceratosaurus can not be determined. Possibly a 
process of the bone extended forward outside of the passage against the inner face of the maxilla.

A comparison of the palate of Ceratosaurus with that of Diplodocus, as represented by Marsh ${ }^{a}$ brings to light both differences and resemblances that are interesting. In describing the palate of Diplodocus it will be convenient to regard it as divided into anterior, second, third, and posterior fourths. In this genus, as in Ceratosaurus, the pterygoids extend far forward, to come into contact with the small vomers. Along the midline they are applied to each other backward nearly to a line joining the articular ends of the quadrates at the hinder end of the third quarter of the length. In the lizard Cyclura they diverge about the middle of the length of the skull. In Diplodocus the postero-inferior process of the pterygoid is very short, on account of the forward swing of the quadrate. Thus the basipterygoid processes join the pterygoids but little in front of the articular ends of the quadrates.

The anterior position of the articular ends of the quadrates has not been acquired at the expense of the posterior processes of the pterygoids alone. There seems to have occurred in Diplodocus a remarkable shoving forward of structures that in Ceratosaums lie across the second and third quarters of the length of the base of the skull. On examining Marsh's figure of Diplodocus it will be observed that there are four vacuities lying in a row across the palate in the second quarter of the length. The two of these which are nearer the midline are the internal nasal passages; those lying farther outward, right and left, the postpalatine vacuities. In Ceratosaurus, as in Cyclura, the latter are behind the nasal passages, being separated therefrom by the palatine bones. In Diplodocus the postpalatine vacuities seem to have been crowded forward alongside and outside of the nasal openings.

Each postpalatine vacuity is mostly inclosed by the maxilla and its processes, only a little of its hinder end being inclosed by the palatine and the transverse bone. The hinder end of the nasal passage lies between the forks of the small palatine. The rest of its inner border is formed by the slender vomer, while it is bounded in front and outwardly by processes of the maxilla.

${ }^{a}$ Dinosaurs of North America, p. 177, fig. 27. 


\section{$2 \mathrm{BHL}$ Biodiversity Heritage Library}

Hay, Oliver Perry. 1908. "On certain genera and species of carnivorous dinosaurs, with special reference to Ceratosaurus nasicornis Marsh." Proceedings of the United States National Museum 35(1648), 351-366. https://doi.org/10.5479/si.00963801.35-1648.351.

View This Item Online: https://www.biodiversitylibrary.org/item/32327

DOI: https://doi.org/10.5479/si.00963801.35-1648.351

Permalink: https://www.biodiversitylibrary.org/partpdf/27584

\section{Holding Institution}

Smithsonian Libraries

\section{Sponsored by}

Smithsonian

\section{Copyright \& Reuse}

Copyright Status: NOT_IN_COPYRIGHT

This document was created from content at the Biodiversity Heritage Library, the world's largest open access digital library for biodiversity literature and archives. Visit BHL at https://www.biodiversitylibrary.org. 